\title{
INERTIA IN PLANT COMMUNITY STRUCTURE: STATE CHANGES AFTER CESSATION OF NUTRIENT-ENRICHMENT STRESS ${ }^{1}$
}

\author{
D. G. Milchunas and W. K. Lauenroth \\ Department of Rangeland Ecosystem Science and Natural Resource Ecology Laboratory, \\ Colorado State University, Fort Collins, Colorado 80523 USA
}

\begin{abstract}
Water, nitrogen, and water-plus-nitrogen at levels beyond the range normally experienced by shortgrass steppe communities were applied from 1971 through 1975, plant populations were sampled through 1977, and the results of the experiment were published. Upon revisiting the plots in 1982, we found it apparent that large changes had occurred since 1977. Sampling was re-established in 1982 to follow trajectories of recovery. Our purposes in this paper are to examine how conclusions from this study changed through time, and discuss implications of these changes for monitoring potentially stressed ecosystems.

Although productivities increased, dissimilarities in plant species composition at the end of the $5 \mathrm{yr}$ of nutrient treatments were not significantly different from controls. Two years after cessation of the treatments exotic "weed" species were increasing in waterplus-nitrogen treated communities, and community dissimilarities were diverging in water and water-plus-nitrogen treated communities. Seven years after cessation of treatments all communities were significantly different from controls. Exotics were more than ten times more abundant in water-plus-nitrogen and nitrogen treated communities than they had been 2 yr post-treatment. A consistent trend in recovery of all treated communities was evident over the next 5 yr. However, the trend towards recovery reversed over the next four consecutive years in the previously water-plus-nitrogen and water treated communities. The four-to-five year cycles in species composition and abundance of exotics towards, and then away from, conditions in undisturbed control communities were not related to weather, but large accumulations of litter suggested biotic regulation.

Inertia of existing plant populations, or the tendency to continue to occupy a site when conditions become unfavorable, can mask both future deterioration in ecosystem condition and unstable behavior resulting from environmental stressors. Time lags in initial response means that an ecosystem can pass a threshold leading to transitions to alternate states before it is evident in structural characteristics such as species composition. Global climate change and sulfur and nitrogen oxide pollutants also have the potential to act as enrichment-stressors with initial time lags and/or positive effects and cumulative, subsequent negative effects, rather than as disturbance forces with immediate negative impacts. Sociopolitical systems, however, often require change in biological variables or negative impacts before acting to ameliorate environmental problems. The manner in which conclusions changed at various periods in time, and the potential for time lags in responses of species populations, raises questions about which variables are most useful for detection of stress and how long studies must last to be useful.
\end{abstract}

Key words: disturbance; exotic weed invasions; long-term monitoring; nutrient enrichment; population oscillations; semiarid grassland; stability; succession; time lags.

\section{INTRODUCTION}

Environmental policy makers rely upon scientific observations and experiments for information, but inertia of biological communities in the presence of stressors could profoundly affect whether appropriate policy decisions are reached. Our use of the term "inertia" is in the sense of paleoecologists, who use it to describe time lags in response of populations to changes in climate (Gorham 1957, Cole 1985). In this paper we demonstrate that inertia can be more than just a time lag

\footnotetext{
${ }^{1}$ Manuscript received 13 October 1993; revised 8 April 1994; accepted 6 May 1994
}

in response to an ongoing stressor. Inertia can mask a threshold of response; a community can change to an alternate state even after a stressor is removed. Species monitoring may provide delayed indicators of stress, and short-term experimental studies may lead to erroneous inferences about long-term consequences of stressors. Inertia may be important in considerations of human-caused stressors such as nitrogen and sulfur oxide pollution and climate change. We present empirical evidence of inertia in shortgrass steppe plant communities exposed to nutrient enrichment. The degree to which conclusions changed through time emphasizes the importance of long-term studies in assessing the effects of stressors or disturbances on ecosystems. 
Shortgrass steppe plant communities were subjected to $5 \mathrm{yr}$ (1971-1975) of water, nitrogen, and water-plusnitrogen treatments at levels beyond the range normally experienced by the system. The original objectives of the experiment were formulated at a time when theory concerning the effects of disturbances such as nutrient enrichments on succession and diversity were receiving considerable attention (Odum 1969, Rosenzweig 1971, Hurd and Wolf 1974). These treatments were sampled through 1977 under the International Biological Program. Our original objectives, upon re-examining the communities in 1982, were to compare them with other natural large-scale disturbances (Milchunas et al. 1990) and test hypotheses concerning stability and pathways of recovery. It was not until after uniting the old and new data sets, and following the communities for an additional $10 \mathrm{yr}$, that the unusual behaviors were fully apparent. Our objectives will be to assess the temporal sequences of changes in species composition of these plant communities, present possible conclusions that might have been drawn had monitoring ceased at various points in time, and discuss implications for monitoring condition and trend in potentially stressed ecosystems.

\section{METHODS}

The study site is located at the Central Plains Experimental Range (CPER) in the northern portion of the shortgrass steppe $\approx 60 \mathrm{~km}$ northeast of Fort Collins, Colorado, USA (Lat. $40^{\circ} 49^{\prime} \mathrm{N}$, Long. 104 $46^{\prime} \mathrm{W}$ ). Mean annual precipitation over the past 52 yr was 321 $\pm 98 \mathrm{~mm}$ [mean $\pm 1 \mathrm{sD}$ ], $71 \%$ of which occurred during the May-September growing season (Lauenroth and Sala 1992). Mean monthly air temperatures range from $-5^{\circ} \mathrm{C}$ in January to $22^{\circ} \mathrm{C}$ in July. The semiarid shortgrass steppe is dominated by the drought- and grazing-tolerant bunchgrass Bouteloua gracilis (H.B.K.) Lag. Other important species in undisturbed communities include Opuntia polyacantha Haw., Sphaeralcea coccinea (Pursh) Rydb., and Artemisia frigida Willd. Total basal cover is typically 25-35\% (Milchunas et al. 1989). Densities of opportunistic, exotic, "weed" species are low in undisturbed communities, even those heavily grazed for $50 \mathrm{yr}$ by domestic livestock (Milchunas et al. 1989, 1992).

Control, water, nitrogen, and water-plus-nitrogen treatments were initiated in 1971 (Lauenroth et al. 1978, Dodd and Lauenroth 1979). The experimental design consisted of two replications of factorial combinations of water and nitrogen, with each treatmentreplicate extending over a 1-ha area, and the treatments applied from 1971 to 1975 . The objective of the water treatment was to maintain soil water potential above $-0.03 \mathrm{MPa}$ in the surface $10 \mathrm{~cm}$ of soil during the growing season. Water was applied through a sprinkler irrigation system, and water additions averaged $590 \pm$ $80 \mathrm{~mm} / \mathrm{yr}$ [mean $\pm 1 \mathrm{sD}$ ] over the $5 \mathrm{yr}$ of treatment. The objective of the nitrogen treatment was to maintain a difference of at least $50 \mathrm{~kg} / \mathrm{ha}$ of soil mineral nitrogen between treatment and control. Ammonium-nitrate applications ranged from 100 to $150 \mathrm{~kg} \cdot \mathrm{ha}^{-1} \cdot \mathrm{yr}^{-1}$. The nutrient enrichments were considered ecosystem-level stressors because they represented conditions not previously experienced by the ecosystem: essentially unlimited supply of water and/or nitrogen within the zone of maximum root biomass.

Treatments were terminated in 1975, after $5 \mathrm{yr}$, and vegetation was sampled through 1977 (Lauenroth et al. 1978, Dodd and Lauenroth 1979). Sampling was resumed in 1982 by sampling 10 permanent plots on each of five transects in each of the treatment-replicates (4 treatments $\times 2$ locations $\times 50$ plots). Densities of species were determined at each permanent plot by counting all individuals in $0.25-\mathrm{m}^{2}$ circular quadrats at the time of peak standing crop in mid to late July. Because many of the plants are clonal, individuals were defined as tillers or stems emerging at ground level and the number of live cactus cladodes (pads). Basal cover was determined at each plot using an inclined 10-point frame.

Data were analyzed using a split-plot type repeatedmeasures analysis of variance. The error terms were tested for significance and pooled whenever possible. Confidence intervals for means separation are Tukey HSDs $(P \leq 0.05)$. Whittaker's index of association (Whittaker 1952) was computed, using log-transformed density data, to compare dissimilarities between entire communities. The Whittaker index and transformation of data were chosen because the shortgrass steppe is heavily dominated by a single species $(B$. gracilis) and other indices and/or use of non-transformed data resulted in values that tracked changes in this species alone or only responded to the presence or absence of the three to four most abundant species. Confidence intervals were calculated by the bootstrap percentile method (Efron 1981). The 95\% confidence intervals should be used conservatively, however, because simulation studies indicate that the percentile method results in confidence interval coverage rates that are typically low (Schenker 1985). Nominal 95\% confidence intervals may have coverage rates closer to $90 \%$.

\section{RESULTS}

At the end of the treatment period in 1975, densities of $B$. gracilis in the nutrient-enriched communities were $\geq$ those in controls and there were few individuals of exotic species (Fig. 1A, B). Based upon data collected through the 1974 growing season, Lauenroth et al. (1978) concluded that the nitrogen treatment had only small effects on plant community composition. The watered communities, although dissimilar from control communities in some respects, were judged to be "still recognizable at least structurally as a shortgrass type." The water-plus-nitrogen communities were assessed as still having "structural affinities to the shortgrass prairie," but their productivities were so 

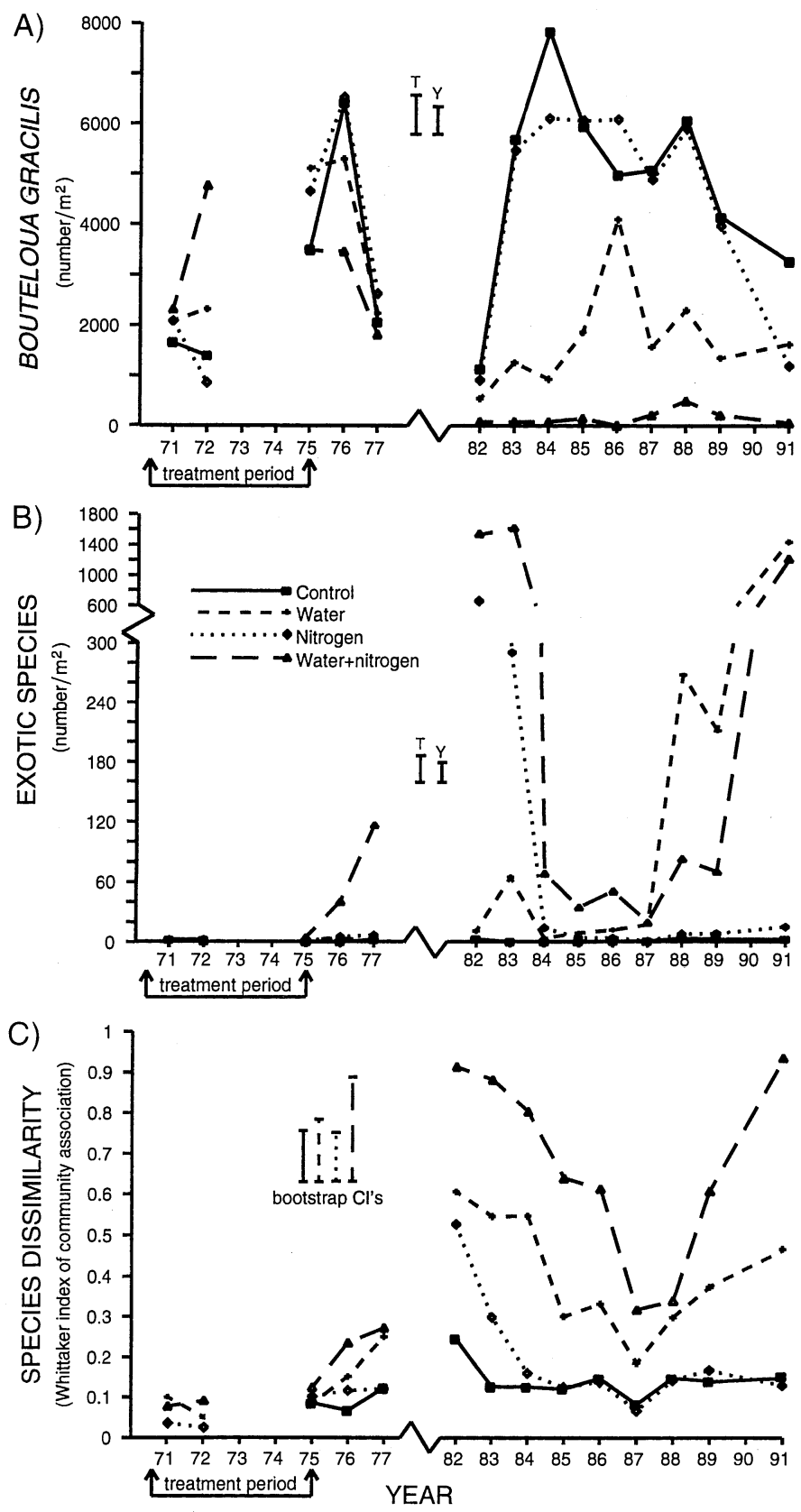

FIg. 1. (A) Density of Bouteloua gracilis tillers in control and water-, nitrogen-, and water-plus-nitrogen-enrichment treatments during the first two and the last year of the 5-yr stress-treatment period, 1 and 2 and 7 through $16 \mathrm{yr}$ after cessation of treatments. Confidence intervals (Tukey's HSD, $P \leq$ 0.05 ) with letter " $T$ " are for comparing treatments within years, and " $Y$ " for years within treatments. (B) Density of exotic (invader"weed") species for treatments and years described above. There were a total of 10 different exotic species recorded, with Kochia scoparia, Salsola iberica, Sisymbrium altissimum, and Cirsium arvense the most abundant. Populations of native opportunistic "weed" species were distributed among treatments and years in a fashion similar to that shown for the introduced and naturalized exotic species. (C) Species dissimilarity of control replicate no. 1 vs. control replicate no. 2, and each nutrient-enrichment treatment replicate vs. its respective control within a particular year. A value of " 1 " indicates no species in common between the two communities that are contrasted, and a value of " 0 " indicates all species in common and each in the same proportion in the two contrasted communities. Values were calculated using density data and Whittaker's (1952) index of community association. Bootstrap CI's are bootstrap confidence intervals. much greater that it was suggested that a new state may have been reached. Because the basic component species of shortgrass steppe were still present, indices of the degree of overlap in community composition or species dissimilarities of the water-plus-nitrogen communities compared to controls were not significantly different at the end of treatment in 1975 (Fig. 1C). A rapid return to general shortgrass steppe characteristics, and a slow successional return to ground state or control conditions, was predicted (Lauenroth et al. 1978).

During the $2 \mathrm{yr}$ following cessation of the treatments, exotic species increased in the water-plus-nitrogen communities (Fig. 1B). B. gracilis (and other species abundant in undisturbed shortgrass steppe) increased in control and nitrogen communities in 1976, but not in the water and water-plus-nitrogen communities, and decreased sharply in all communities in 1977 (Fig. 1A). Based upon all species, dissimilarity indices indicated a trend away from control conditions by 1977 in both water and water-plus-nitrogen communities, but not in the nitrogen communities (Fig. 1C). However, B. gracilis still dominated all communities.

Seven years after cessation of treatments (1982), the treated plant communities were significantly dissimilar from control communities (Fig. 1C). As a result of invasion by exotic species, the water-plus-nitrogen 
FIG. 2. Annual, warm-season, and coolseason precipitation for the Central Plains Experimental Range from 1970 through 1991. Different periods shown are based upon frost-free period (May 15-Sep 15), or effective precipitation for that year up to time of sampling for the March-July period.

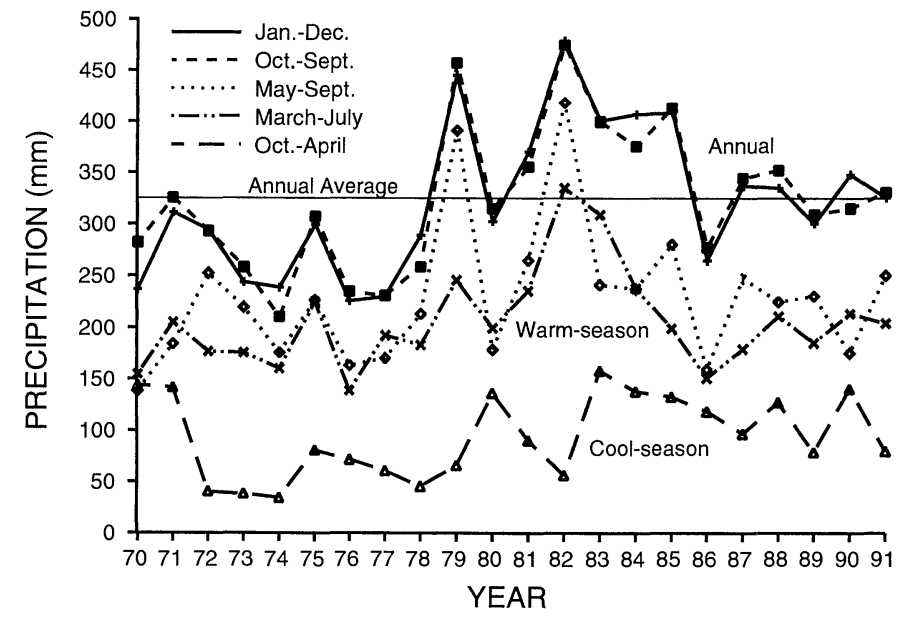

communities were very different from the controls, and from their previous composition during and shortly after the treatment years. The watered communities were the next most dissimilar from controls. This was not because of invasions by exotic species (Fig. 1B, C), but because of increases in native grasses other than B. gracilis. By contrast, species composition of the nitrogen-enriched communities closely tracked controls but had an additional component of exotic species at high densities.

From 7 to $12 \mathrm{yr}$ following cessation of treatments (1982-1987), all stressed communities gradually approached the structure of control communities (Fig. 1C). Populations of exotic species decreased over this time period (Fig. 1B). B. gracilis and other native species increased in water and water-plus-nitrogen communities even during years when they declined in control communities (Fig. 1A). At this time, it appeared that the stress-communities were recovering. However, these trends reversed in the water-plus-nitrogen communities during subsequent years (1988-1991). Exotic species invaded the watered communities, but not the nitrogen-enriched communities, which was the opposite of what had occurred 7 and $8 \mathrm{yr}$ after cessation of the treatments (Fig. 1B).

The fluctuations in abundances of exotic species and indices of community dissimilarity did not appear to be directly correlated with precipitation. While 19791985 was a generally wet period, densities of exotics were high in 1982-1983 but low in 1984-1987 (Fig. 1B, Fig. 2). Precipitation from 1987 to 1991 was close to average levels, but exotics generally increased from 1987 to 1991 . While the progressive decline in species dissimilarities of nutrient enriched communities from 1982 to 1987 followed a general decline in precipitation, the progressive increase from 1987 to 1991 was not related to precipitation.

\section{DISCUSSION}

Humans are accustomed to thinking of disturbances as having immediate, observable, negative effects, but enrichment stressors often cause positive immediate effects that may not be indicative of long-term effects. The nitrogen and water treatments we examined represented the addition of nutrients essential to all plant and animal life, much the same as sulfur and nitrogen in $\mathrm{SO}_{2}$ and $\mathrm{NO}_{\mathrm{x}}$ pollution, and carbon in $\mathrm{CO}_{2}$ (Lauenroth and Milchunas 1985, Field et al. 1992). Exposure to such compounds at low or moderate levels often causes positive fertilization responses initially (Lauenroth and Milchunas 1985, Aber et al. 1989). Cumulative effects of nutrient enrichment on ecosystems may be no less devastating than discrete well-defined disturbances, but the development of effects over time may be very different. Rosenzweig (1971) mathematically showed the potential for destabilizing ecosystems through nutrient enrichment, and termed the phenomenon the "paradox of enrichment". The paradox was that what appeared to be a positive action, "to enrich an ecosystem in order to increase its food yield", could "end in catastrophe". The modeled system was a simple two-species interaction, and time lags were not included. The complexity of a system, the life history characteristics, competitive abilities, and plasticity or adaptability of the components, and the availability of invader species can be important determinants of both the time lag and magnitude of changes in complex communities. In some cases, changes in community composition in response to nutrient additions can take long periods of time. Tilman (1989) described results from the plots in the Park Grass Experiment of Rothamsted, England, which have been fertilized with nitrogen for the past 130 yr. Changes in plant community composition have gradually taken place over the entire 130 $y r$, due either to a long period of dominance by species that were later displaced or to the slow changes in soil $\mathrm{pH}$.

Although our enrichment treatments were terminated in 1975 , there is the question of residual nutrients. Potential nitrogen mineralization of the soil (laboratory incubations) and nitrogen concentrations of above- 
ground plant tissue were higher in our nitrogen treatments than in controls in 1991 (M. A. Vinton, unpublished data). However, residual water would be expected to be depleted $\leq 1 \mathrm{yr}$ after termination of treatment in this semiarid environment. Since cumulative effects are generally viewed in terms of direct accumulation of the primary stressor, one may question whether the inertia displayed by the water-treated communities was primarily a function of occupation of space by existing plants resulting in delayed displacement or a time lag in response to indirect effects of the stressors.

The potential for time lags in community responses to stressors raises the question about which variables are most useful for detection of ecological stress and how long studies must last to be useful. Ecosystems are hierarchically organized, and a force applied at one level can be damped or amplified at another level (O'Neill et al. 1986). We monitored only plant population density and basal cover during the post-treatment years. Were there indications of the consequences of the stressors during treatment years based upon other variables? End-of-season aboveground biomass increased 56, 57, and $265 \%$ over controls for the water, nitrogen, and water-plus-nitrogen treatments, respectively, during the first year of treatment, and increased 68,50 , and $240 \%$ during the fourth year of treatment (Lauenroth et al. 1978). An increase in the biomass of exotic invader species was observed in the water-plusnitrogen sites by the end of the treatments, and the suggestion was made, based upon observations $2 \mathrm{yr}$ after cessation of treatments, that these species may be on the way to replacing the dominant warm-season grasses (Dodd and Lauenroth 1979). Ground covered by litter in the nitrogen-plus-water treatments averaged $91 \%$ compared to 63,41 , and $36 \%$ for water, nitrogen, and control treatments, respectively, in the year (1983) of peak litter accumulation $8 \mathrm{yr}$ after cessation of the treatments.

Inhibition of recruitment by litter has been suggested as a feedback mechanism causing oscillations and chaotic dynamics of more productive grassland communities (Tilman and Wedin 1991) than the shortgrass steppe. Such a feedback may be operating in our nutrient enriched communities, but it has not been demonstrated and observations of litter could not be used to predict subsequent changes in plant populations. We hypothesize that the infrequent and slow spread by seedling recruitment of the dominant shortgrass $B$. gracilis (Briske and Wilson 1977, Lauenroth et al. 1994), in conjunction with weed-litter accumulation followed by slow decomposition to a level allowing another episode of weed recruitment, may be operating to produce the oscillations. Shifting the system from one dominated by perennial plants, in which belowground processes account for the interactions among plants, to one dominated by annual plants, in which aboveground interactions are important, increases the significance of the accumulation of litter on the temporal dynamics. Allelopathy of Kochia scoparia litter (Lodhi 1979) may be an additional factor on the waterplus-nitrogen treatment.

We have only indirect evidence that a shift from a belowground- to an aboveground-dominated system may have occurred. In a separate experiment, we observed that plots that were cleared and seeded to annual, "weed" species such as those common in the water-plus-nitrogen treatment produced two and a half to three times more aboveground biomass than native shortgrass steppe (Milchunas et al. 1992). Since primary production of non-fertilized, semiarid shortgrass steppe is most frequently controlled by water and it is unlikely that annual "weeds" are three times more efficient in water use than native perennials, increases in aboveground production are probably compensated for by decreases in belowground production. Root/shoot biomass ratios from cores taken directly over individual plants were 4 for $B$. gracilis compared to $<1.5$ for Kochia scoparius growing on the water-plus-nitrogen treatments in 1991 (M. A. Vinton, unpublished data).

The development and testing of "ecological indicators" is an objective of monitoring programs such as the Environmental Monitoring and Assessment Program of the U.S. Environmental Protection Agency (Linthurst et al. 1992). Even in retrospect, it would be difficult to suggest an indicator that could have been used to predict the chaotic behavior of our post-treatment communities.

Oscillations following initial changes in composition are sometimes observed in disturbed or stressed communities (Nunney 1985). The amplitude of oscillations and whether they are patterned, random, or chaotic are often not predictable because of complex feedbacks, buffering mechanisms, and indirect effects. Time lags in ecological responses superimpose an additional level of complexity on this problem. The effects of stressors can accumulate through time and create unstable conditions before changes are evident in a particular system component. In a discussion of conceptual problems for field experiments, Tilman (1989) presented results from a few of the small number of experiments that have been continued or monitored for $>5$ field seasons (only $1.7 \%$ of field experiments based upon his survey). A common conclusion drawn from these long-term studies was that the outcomes of field-manipulation experiments were time dependent, i.e., conclusions based upon short-term results can be opposite to those based upon long-term results. The studies that Tilman examined included both single-pulse manipulations and continuous treatments. While also showing that conclusions can change through time, our study illustrates that a threshold leading to transient dynamics or a potential alternate state can be reached before it is apparent in species composition.

The current level of human activities has created a large potential for enrichment stressors at regional and 
global scales (Melillo 1989). We suggest that questions concerning specific trajectories of disturbed communities are secondary to establishing whether stress-related changes in processes are occurring and if or when a threshold will be reached causing major structural changes. Environmental monitoring and assessment programs need to consider multi-variable, hierarchical approaches based upon linking nutrient deposition with functional aspects of ecosystems. Defining "critical loads" for various ecosystems may require the monitoring of retention (Aber et al. 1993) and process changes in order to avert structural changes. Aquatic systems with rapid turnover of short-lived species can react to stress very differently from our terrestrial example with long-lived perennial plants. A long-term study of lake acidification showed dramatic changes in population structure of phytoplankton and benthic crustaceans, but only small changes in primary production and decomposition (Schlindler et al. 1985). Division of ecosystems into those dominated by short-lived or long-lived organisms may prove to be useful in predicting responses to stressors. Judicious policy decisions cannot be made without consideration of deposition, retention, alteration of processes, and structural changes rather than single-variable indicators.

The ways in which ecological data are used for human policy making must account for possible delayed and unexpected responses (Loucks 1985). Inertia in community structure can mean that extant populations are remnants adapted to an environment of the past.

\section{ACKNOWLEDGMENTS}

We thank Paul Hook, Mike Coughenour, and Mary Ann Vinton for reviewing various drafts of the manuscript and providing constructive criticism and suggestions. This is a contribution of the Shortgrass Steppe Long-Term Ecological Research Program (NSF BSR-8114822) and the Colorado Agricultural Experiment Station (1-57661). The USDA-Agricultural Research Service administers the CPER.

\section{Literature Cited}

Aber, J. D., A. Magill, R. Boone, J. M. Melillo, P. Steudler, and R. Bowden. 1993. Plant and soil responses to chronic nitrogen additions at the Harvard Forest, Massachusetts. Ecological Applications 3:156-166.

Aber, J. D., K. J. Nadelhoffer, P. Steudler, and J. M. Melillo. 1989. Nitrogen saturation in northern forest ecosystems. BioScience 39:378-386.

Briske, D. D., and A. M. Wilson. 1977. Temperature effects on adventitious root development in blue grama seedlings. Journal of Range Management 30:276-280.

Cole, K. 1985. Past rates of change, species richness, and a model of vegetation inertia in the Grand Canyon, Arizona. American Naturalist 125:289-303.

Dodd, J. L., and W. K. Lauenroth. 1979. Analysis of the response of a grassland ecosystem to stress. In $\mathrm{N}$. $\mathrm{R}$. French, editor. Perspectives in grassland ecology. Ecological Studies Analysis and Synthesis 32:43-58.

Efron, B. 1981. Nonparametric standard errors and confidence interval. Canadian Journal of Statistics 9:139-172.

Field, C. B., F. S. Chapin III, P. A. Matson, and H. A. Mooney. 1992. Responses of terrestrial ecosystems to the changing atmosphere: a resource-based approach. Annual Review of Ecology and Systematics 23:201-235.

Gorham, E. 1957. Development of peatlands. Quarterly Review of Biology 32:145-166.

Hurd, L. E., and L. L. Wolf. 1974. Stability in relation to nutrient enrichment in arthropod consumers of old field successional ecosystems. Ecological Monographs 44:465482.

Lauenroth, W. K., J. L. Dodd, and P. L. Sims. 1978. The effects of water- and nitrogen-induced stresses on plant community structure in a semiarid grassland. Oecologia (Berlin) 36:211-222.

Lauenroth, W. K., and D. G. Milchunas. 1985. $\mathrm{SO}_{2}$ effects on plant community function. Pages 454-477 in W. E. Winner, H. A. Mooney, and R. A. Goldstein, editors. Sulfur dioxide and vegetation. Stanford University Press, Stanford, California, USA

Lauenroth, W. K., and O. E. Sala. 1992. Long-term forage production on North American shortgrass steppe. Ecological Applications 2:397-403.

Lauenroth, W. K., O. E. Sala, D. P. Coffin, and T. B. Kirchner. 1994. The importance of soil water in the recruitment of Bouteloua gracilis in the shortgrass steppe. Ecological Applications 4:741-749.

Linthurst, R. A., K. W. Thornton, and L. E. Jackson. 1992. Integrated monitoring of ecological conditions: issues of scale, complexity and future change. Pages 1421-1443 in D. H. McKenzie, D. E. Hyatt, and V. J. McDonald, editors. Ecological Indicators. Volume II. Elsevier Applied Science, London, England.

Lodhi, M. A. K. 1979. Germination and growth of Kochia scoparia in relation to its autoallelopathy. Canadian Journal of Botany 57:1083-1088.

Loucks, O. L. 1985. Looking for surprise in managing stressed ecosystems. BioScience 35:428-432.

Melillo, J. M., P. A. Steudler, J. D. Aber, and R. D. Bowden. 1989. Atmospheric deposition and nutrient cycling. Pages 263-279 in M. O. Andreae and D. S. Schimel, editors. Exchange of trace gases between terrestrial ecosystems and the atmosphere. John Wiley and Sons, New York, New York, USA.

Milchunas, D. G., W. K. Lauenroth, and P. L. Chapman. 1992. Plant competition, abiotic, and long- and short-term effects of large herbivores on demography of opportunistic species in a semiarid grassland. Oecologia 92:520-531.

Milchunas, D. G., W. K. Lauenroth, P. L. Chapman, and M. K. Kazempour. 1989. Effects of grazing, topography, and precipitation on the structure of a semiarid grassland. Vegetatio 80:11-23.

Milchunas, D. G., W. K. Lauenroth, P. L. Chapman, and M. K. Kazempour. 1990. Community attributes along a perturbation gradient in a shortgrass steppe. Journal of Vegetation Science 1:375-384.

Nunney, L. 1985. Short time delays in population models: a role in enhancing stability. Ecology 66:1849-1858.

Odum, E. P. 1969. The strategy of ecosystem development. Science 164:262-270.

O'Neill, R. V., D. L. DeAngelis, J. B. Wade, and T. F. H. Allen. 1986. A hierarchical concept of ecosystems. Monographs in Population Biology 23.

Rosenzweig, M. L. 1971. Paradox of enrichment: destabilization of exploitation ecosystems in ecological time. Science 171:385-387.

Schenker, N. 1985. Qualms about bootstrap confidence intervals. Journal of the American Statistical Association 80: 360-361.

Schlindler, D. W., K. H. Mills, D. F. Malley, D. L. Findlay, J. A. Shearer, I. J. Davies, M. A. Turner, G. A. Linsey, and D. R. Cruikshank. 1985. Long-term ecosystem stress: the 
effects of years of experimental acidification on a small lake. Science 228:1395-1401.

Tilman, D. 1989. Ecological experimentation: strengths and conceptual problems. Pages 136-157 in G. E. Likens, editor. Long-term studies in ecology. Springer-Verlag, New York, New York, USA.
Tilman, D., and D. Wedin. 1991. Oscillations and chaos in the dynamics of a perennial grass. Nature 353:653-655.

Whittaker, R. H. 1952. A study of summer foliage insect communities in the Great Smoky Mountains. Ecological Monographs 22:1-44. 